Article

\title{
Increasing Fuel Efficiency of Direct Methanol Fuel Cell Systems with Feedforward Control of the Operating Concentration
}

\author{
Youngseung $\mathrm{Na}^{1,3, \dagger}$, Federico Zenith ${ }^{2, \dagger}$ and Ulrike Krewer ${ }^{1, *}$ \\ ${ }^{1}$ Institute of Energy and Process Systems Engineering, TU Braunschweig, Franz-Liszt-Str. 35, \\ Braunschweig 38106, Germany; E-Mail: y.na@tu-braunschweig.de \\ ${ }^{2}$ SINTEF Applied Cybernetics, PO Box 4760 Sluppen, Trondheim NO-7465, Norway; \\ E-Mail: Federico.Zenith@ sintef.no \\ ${ }^{3}$ International Max Planck Research School for Advanced Methods in Process and Systems \\ Engineering, Sandtorstr. 1, Magdeburg 39106, Germany \\ $\dagger$ These authors contributed equally to this work. \\ * Author to whom correspondence should be addressed; E-Mail: u.krewer@tu-braunschweig.de; \\ Tel.: +49-531-391-3030; Fax: +49-531-391-5932.
}

Academic Editor: Akhtar Kalam

Received: 16 June 2015 / Accepted: 14 September 2015 / Published: 21 September 2015

\begin{abstract}
Most of the R\&D on fuel cells for portable applications concentrates on increasing efficiencies and energy densities to compete with other energy storage devices, especially batteries. To improve the efficiency of direct methanol fuel cell (DMFC) systems, several modifications to system layouts and operating strategies are considered in this paper, rather than modifications to the fuel cell itself. Two modified DMFC systems are presented, one with an additional inline mixer and a further modification of it with a separate tank to recover condensed water. The set point for methanol concentration control in the solution is determined by fuel efficiency and varies with the current and other process variables. Feedforward concentration control enables variable concentration for dynamic loads. Simulation results were validated experimentally with fuel cell systems.
\end{abstract}

Keywords: fuel cell system; concentration; control 


\section{Introduction}

Fuel cell systems are already commercialized for certain applications: for larger applications, solid oxide fuel cells, molten carbonate fuel cells and phosphoric acid fuel cells are used as small power plants or residential combined heat and power generators. Polymer electrolyte fuel cells are utilized in fuel cell-powered electric vehicles or for portable uses [1,2]. Among polymer electrolyte fuel cells, direct methanol fuel cells are considered to be the most appropriate for portable electric generation, because of their small size and the high energy density of methanol [3]. The basic reactions in the direct methanol fuel cell (DMFC) are the anodic and cathodic reactions:

$$
\begin{array}{rr}
\mathrm{CH}_{3} \mathrm{OH}+\mathrm{H}_{2} \mathrm{O} & \longrightarrow \mathrm{CO}_{2} \uparrow+6 \mathrm{H}^{+}+6 \mathrm{e}^{-} \\
6 \mathrm{H}^{+}+6 \mathrm{e}^{-}+\frac{3}{2} \mathrm{O}_{2} & \longrightarrow 3 \mathrm{H}_{2} \mathrm{O}
\end{array}
$$

Much research on membrane electrode assemblies [4], gas diffusion layers [5], other components [6] or stacks [7] has been carried out on the optimization of the design parameters to improve efficiencies. Fuzzy logic techniques can optimize fuel cell efficiencies with multiple objectives [8]. The basic background of this study is based on the research of Arisetty et al. [9], which shows that in a DMFC, there is an optimal methanol concentration, at which the efficiency of the fuel cell reaches a maximum. To quantify the implications of this finding on the design of autonomously-operating systems, we developed and compared three different DMFC system designs.

A reference system where each component serves only one function (Figure 1) has already been investigated by Zenith and Krewer [10]. In that system, the recycled solution from the degasser and the recycled water from the condenser are collected and are joined with neat methanol in a relatively large mixer to mitigate concentration fluctuation. The well-blended solution from this mixer is then supplied to the DMFC's anode inlet. Since the dynamics of methanol concentration in the anodic loop is stable, it is possible to control it without measurement or feedback; this concept has been validated in experiments without feedback control of the concentration [11]: the reference system was shown to be able to maintain a constant concentration during operation. However, the reference system cannot change the concentration rapidly, because of the slow concentration transients in the large mixer; in particular, it cannot promptly adapt the concentration to the stack current. In this study, we investigated two different system designs able to control concentration more rapidly and thereby attain greater efficiency in accordance with the findings of Arisetty et al. [9]. Mathematical models of these systems, including peripheral devices, were implemented in a dynamic simulation and validated.

\section{Systems}

The reference system has one mixer to blend three flows of different compositions: the solution from the degasser has methanol concentrations ranging from $0.1 \mathrm{M}$ to $2 \mathrm{M}$ according to the operating conditions; the liquid from the condenser is neat water; and the liquid from the methanol tank is neat methanol. To join these different concentrations into a well-blended solution, the reference system is equipped with a mixer [10]. However, this system is not able to instantaneously adjust the concentration of the solution entering the anode, because the large size of the mixer works as a buffer to mitigate concentration changes. In the first modification to the reference system, neat methanol is added in 
an inline mixer to the flow coming from the mixer tank, as illustrated in Figure 2. In this two-mixer system, recycled methanol solution and condensed water are first blended in the large tank mixer; the diluted solution is subsequently concentrated by neat methanol in an inline mixer with negligible holdup to increase the anode inlet concentration to its optimal value. This feedforward concentration control enables responding promptly to sudden changes in the electric load.

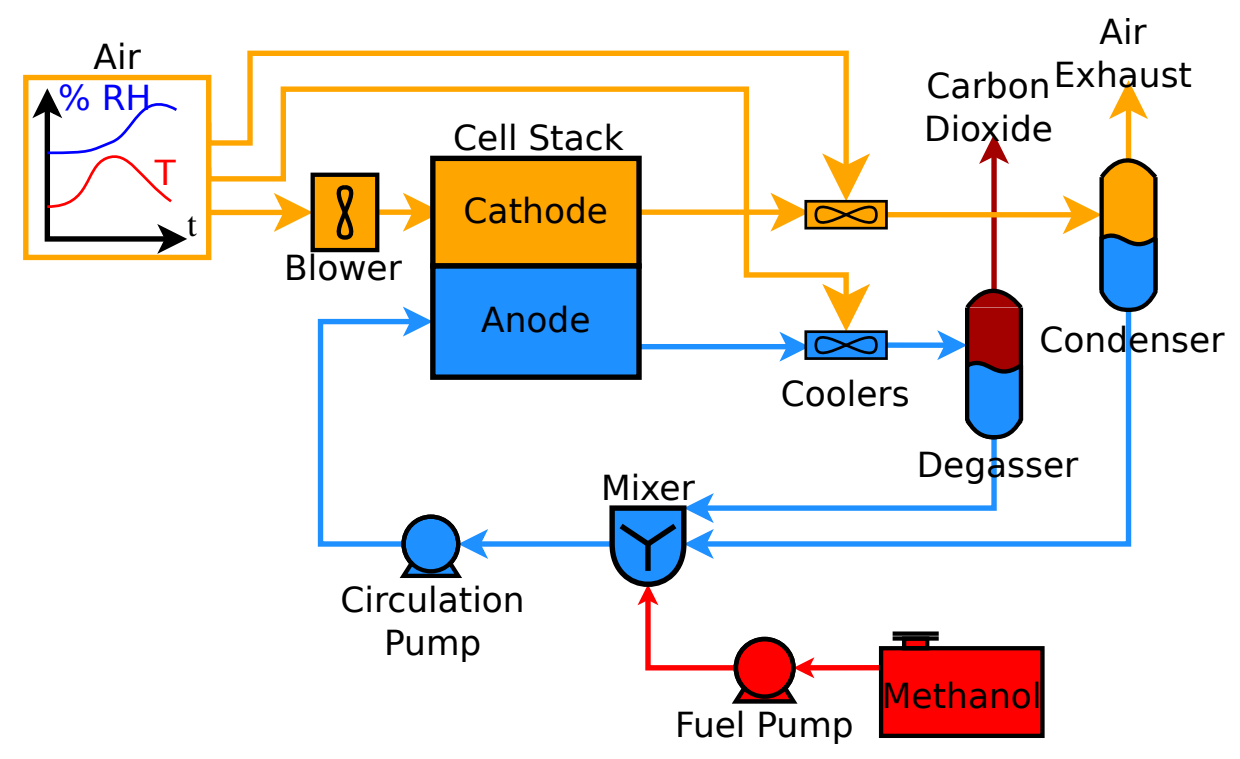

Figure 1. The process layout of the reference system [10].

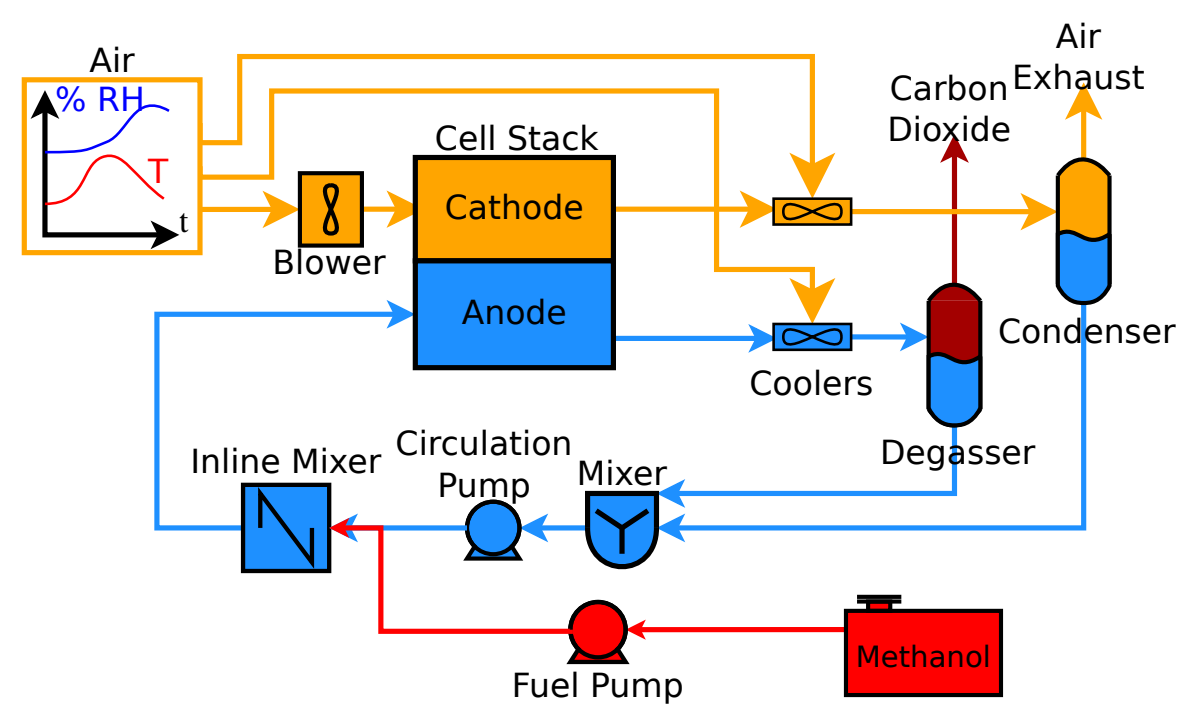

Figure 2. The process layout of the two-mixer system.

To obtain a further degree of freedom to control the concentration, a system with separated solution tanks is also suggested (Figure 3), employing separate reservoirs for spent solution and condensed water. In this layout variation, the methanol concentration can be not only increased, as in the previous two-mixer layout, but also decreased by adding neat water. When the required concentration is smaller than that of the recycled solution, both the reference and the two-mixer system need to wait until the 
excess methanol is consumed in the fuel cell. In contrast, the separate tank system can immediately decrease the concentration with the additional water tank.

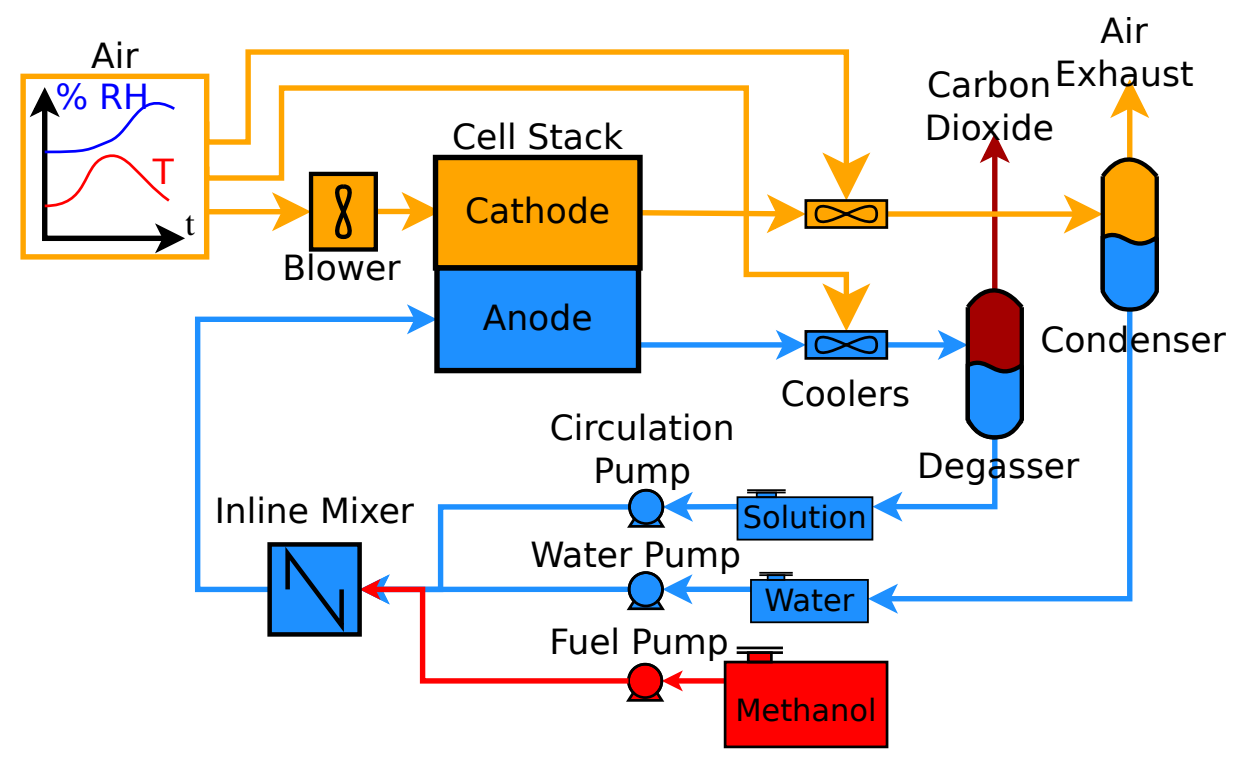

Figure 3. The process layout of the separate tank system.

The two new suggested systems are modeled in the declarative and object-oriented programming language Modelica 3.0, programmed with Dymola 7.4. The simulations have then been validated with laboratory experiments. The detailed models are explained in the next section.

\section{Methods}

\subsection{Modeling}

The fundamental model equations of the fuel-cell system are identical to those given by Zenith and Krewer [10]. The main features of the model will be recapitulated in this section.

\subsubsection{Cell Model}

Methanol is consumed in the cell with reactions in Equation (1) at the anode and Equation (2) at the cathode, respectively. In addition, some methanol diffuses through the membrane and reacts instantaneously and completely at the cathode by the overall reaction:

$$
\mathrm{CH}_{3} \mathrm{OH}+\frac{3}{2} \mathrm{O}_{2} \rightarrow \mathrm{CO}_{2}+2 \mathrm{H}_{2} \mathrm{O}
$$

The amount of crossover methanol is related to current $I$ and methanol concentration $c^{\text {an }}$ in the anode channels, yielding a linear dependency on both variables [10,12]:

$$
\dot{n}_{x}=N\left(a A c^{\text {an }}-\frac{b}{6 F} I\right)
$$

where $N$ is the number of cells and $a$ and $b$ are cell parameters, which can be affected by temperature [13]. 
The relationship between voltage, $U$, and current is simplified in this simulation and is assumed to be a Thévenin equivalent circuit:

$$
U=U_{0}-R I
$$

where $R$ is the overall stack resistance, including electrode losses. Stack parameters $U_{0}$, open circuit voltage and $R$ are experimentally calibrated at $60^{\circ} \mathrm{C}$ with $1 \mathrm{M}$ methanol solution.

The balance equations (T1.1 and T1.2) for the stack are reused from the reference system as shown in Table 1. Water drag by electro-osmosis is assumed (T1.3 and T1.4). In this model, the stack is considered as the only component with heat capacity.

The heat capacity of the stack is estimated to be $3000 \mathrm{~J} / \mathrm{K}$ for the stack used in experimental validation.

Table 1. Model equations and parameters of the reference model [10].

\begin{tabular}{|c|c|c|}
\hline Components & Stack & \\
\hline Component mass balance & $\dot{n}_{j, \text { out }}=\dot{n}_{j, \text { in }}+v_{j} \frac{N \cdot I}{F}+\xi_{j} \dot{n}_{x}$ & $(\mathrm{~T} 1.1)$ \\
\hline Energy balance & $C_{p}^{\text {stack }} \frac{d T^{\text {stack }}}{d t}=\sum_{j, s} h_{j}\left(T_{\text {in }}^{s}\right) \dot{n}_{j, \text { in }}^{s}-\sum_{j, s} h_{j}\left(T^{\text {stack }}\right) \dot{n}_{j, \text { out }}^{s}-U I$ & $(\mathrm{~T} 1.2)$ \\
\hline Electro-osmotic water drag & $\dot{n}_{d}=N \cdot k_{d} \frac{I}{F}$ & $(\mathrm{~T} 1.3)$ \\
\hline $\begin{array}{l}\text { Electro-osmotic drag } \\
\text { coefficient }\end{array}$ & $k_{d}=\left(4.2+\frac{T^{\mathrm{stack}}-303.15 K}{40 K}\right)$ & $(\mathrm{T} 1.4)$ \\
\hline \multirow[t]{5}{*}{ Index } & $j: \mathrm{CH}_{3} \mathrm{OH}, \mathrm{H}_{2} \mathrm{O}, \mathrm{O}_{2}, \mathrm{CO}_{2}, \mathrm{~N}_{2}$ & \\
\hline & $v_{j}^{\text {an }}=\left\{-1 / 6,-1 / 6-k_{d}, 0,1 / 6,0\right\}$ & \\
\hline & $v_{j}^{\text {cath }}=\left\{0,1 / 2+k_{d},-1 / 4,0,0\right\}$ & \\
\hline & $\xi_{j}^{\mathrm{an}}=\{-1,0,0,0,0\}$ & \\
\hline & $\xi_{j}^{\text {cath }}=\{0,2,-3 / 2,1,0\}$ & \\
\hline Components & Separators & \\
\hline \multirow{3}{*}{ Component mass balance } & $\dot{n}_{\mathrm{gas}, j}=\dot{n}_{\mathrm{in}, j}, \quad j \in\left\{\mathrm{O}_{2}, \mathrm{CO}_{2}, \mathrm{~N}_{2}\right\}$ & $(\mathrm{T} .15)$ \\
\hline & $\dot{n}_{\mathrm{gas}, j}=\dot{n}_{\mathrm{in}, j} \frac{\beta K_{j}}{1+\beta\left(K_{j}-1\right)}, j \in\left\{\mathrm{CH}_{3} \mathrm{OH}, \mathrm{H}_{2} \mathrm{O}\right\}$ & $(\mathrm{T} 1.6)$ \\
\hline & $\dot{n}_{\mathrm{liq}, j}=\dot{n}_{\mathrm{in}, j}-\dot{n}_{\mathrm{gas}, j} \quad \forall j$ & $(\mathrm{~T} 1.7)$ \\
\hline Energy balance & $\dot{h}_{\mathrm{liq}}=\sum_{j} h_{j} \times \dot{n}_{\mathrm{liq}, j}$ & $(\mathrm{~T} 1.8)$ \\
\hline Components & Mixer & \\
\hline Component mass balance & $\frac{d n_{j}^{\operatorname{mix}}}{d t}=\sum_{\text {flows }} \dot{n}_{\text {flows }, j}$ & (T1.9) \\
\hline Energy balance & $\frac{d E^{\mathrm{mix}}}{d t}=\sum_{\text {flows }} \dot{h}_{\text {flows }}$ & $(\mathrm{T} 1.10)$ \\
\hline
\end{tabular}




\subsubsection{Peripheral Devices}

Coolers are assumed to be internally cascade-controlled and able to set a given outlet temperature [10]. The degasser and the condenser only separate liquid from gas, which are at perfect equilibrium when leaving the separator (T1.5-T1.7). Energy balance is the summation of each enthalpy of the components (T1.8). The methanol loss by evaporation in the degasser of the reference system is negligible compared to the electrochemical reaction and crossover and can be omitted [14]. The only component that can accumulate materials is the mixer in the system (T1.9). Energy is also dependent on accumulated components (T1.10)

\subsection{Controller Synthesis}

In the reference system, five decoupled SISO (single-input, single-output) controllers govern each control variable, using each manipulated variable; this is summarized in Table 2. Of the five controllers in the reference system, three (oxygen mole fraction $y_{O_{2}}$, condenser temperature $T^{\text {cond }}$ and stack temperature $T^{\text {stack}}$ ) will be maintained unchanged in this study, whereas the concentration controller and the controller for anode excess ratio, $\lambda^{\text {an }}$, will be modified for the two-mixer and the separate tank systems. In addition, the new degree of freedom introduced by the separate tank system, which has the levels of two tanks instead of a single solution tank, will require an extra controller.

Table 2. Summary of the controllers for the reference system [10].

\begin{tabular}{ccccc}
\hline Controlled variable & Manipulated inputs & Disturbance & Measured outputs & Controller type \\
\hline$c_{i n}^{\text {an }}$ & $\dot{V}^{\text {fuel }}$ & $I, T^{\text {deg }}$ & $I$ & Feedforward \\
$\lambda^{\text {an }}$ & $\dot{V}_{\text {in }}^{\text {an }}$ & $I$ & $I$ & Feedforward \\
$y_{\mathrm{O}_{2}}$ & $\dot{V}_{\text {in }}^{\text {cath }}$ & $I$ & $I$ & Feedforward \\
$V^{\text {mix }}$ & $\bar{T}^{\text {cond }}$ & $T^{\text {cond }}, \dot{V}^{\text {cath }}$ & $V^{\text {mix }}$ & Feedback \\
$T^{\text {stack }}$ & $\bar{T}^{\text {deg }}$ & $I, c_{\text {out }}^{\text {an }}$ & $T^{\text {stack }}$ & P feedback \\
\hline
\end{tabular}

\subsubsection{Concentration Set-Point}

The main feature of the two newly-presented layouts (two-mixer and separate tank) is the ability to change the anodic inlet concentration rapidly; it is therefore necessary to present a criterion by which to choose the concentration set-point. The criterion considered in this study is the maximization of the fuel cells' efficiency $\eta$.

There are three components of efficiency to consider:

- Faradaic efficiency $\varphi$,

- Electrochemical efficiency $\varepsilon$ and,

- Thermodynamic efficiency $\eta_{\text {th }}$.

The product of these is the overall system efficiency:

$$
\eta=\varphi \varepsilon \eta_{t h}
$$


Faradaic efficiency $\varphi$ is the ratio of how much methanol is used in the anodic reaction in Equation (1) out of the total that enters the anodic loop, and at the steady state, it is expressed by:

$$
\varphi=N \frac{I}{6 F} \frac{1}{\dot{n}^{\text {fuel }}}
$$

Electrochemical efficiency $\varepsilon$ is instead the efficiency of the conversion from chemical to electrical energy for the combined reactions in Equations (1) and (2); it can be directly inferred from stack voltage:

$$
\varepsilon=\frac{U}{N E^{\mathrm{rev}}}
$$

where $E^{\mathrm{rev}}=\Delta g_{\mathrm{r}} / 6 F$ is the reversible cell potential. Finally:

$$
\eta_{\mathrm{th}}=\frac{\Delta g_{\mathrm{r}}}{\Delta h_{\mathrm{r}}}
$$

where $\Delta h_{r}$ is the enthalpy of reactions in Equations (1) and (2).

This study will focus on faradaic efficiency $\varphi$, since it is the most amenable to study with a system model. The electrochemical efficiency $\varepsilon$ has been previously studied [9], establishing that there is an optimal concentration at which voltage is maximum: higher concentrations promote more crossover (increasing the cathodic overvoltage), and lower concentrations increase anodic overvoltage because of reactant starvation.

Neglecting losses in the degasser, which are relatively small [10], the faradaic efficiency can be approximated with the ratio of methanol consumed in the anodic reaction in Equation (1) to all of the methanol reacted in the fuel cell, including crossover:

$$
\varphi \approx \frac{I / 6 F}{I / 6 F+\dot{n}_{x} / N}
$$

Inserting yields the expression for crossover flow in Equation (4) and solving for anodic concentration:

$$
\bar{c}_{\mathrm{out}}^{\mathrm{an}}=\frac{I}{6 F}\left(\frac{1}{\bar{\varphi}}+\tilde{b}-1\right) \frac{1}{\tilde{a} A}
$$

where $\bar{\varphi}$ is the target faradaic efficiency and $\tilde{a}$ and $\tilde{b}$ are estimates of the crossover parameters.

It is not realistic to simply set the target $\bar{\varphi}=1$, which would imply no crossover: this would mean that the methanol concentration at the anodic catalyst layer would be zero, which would result in reactant starvation and high anodic overvoltage: $\varphi \rightarrow 1$ implies $\varepsilon \rightarrow 0$, bringing total efficiency $\eta$ also to zero.

An exact target faradaic efficiency can be obtained optimizing $\eta$, which in general requires a detailed electrochemical model to calculate $\varepsilon$ as a function of current and methanol concentration; for simplicity, in this study, we will assume a constant target of $\bar{\varphi}=65 \%$ to prevent experimentally-observed fuel deficiency at the anode catalyst layer due to low inlet concentration.

We approximate then that the anode outlet concentration (which is the one that determines crossover in our model) is related to $\lambda^{\text {an }}$ and inlet concentration $\bar{c}_{\text {in }}^{\text {an }}$ in the following way:

$$
\left(\lambda^{\mathrm{an}}-1\right) \bar{c}_{\mathrm{in}}^{\mathrm{an}} \approx \lambda^{\mathrm{an}} \tilde{c}_{\mathrm{out}}^{\mathrm{an}}
$$


Combining Equations (11) and (12) yields:

$$
\bar{c}_{\mathrm{in}}^{\mathrm{an}}=\frac{I}{6 F}\left(\frac{1}{\bar{\varphi}}+\tilde{b}-1\right) \frac{1}{\tilde{a} A} \frac{\lambda^{\mathrm{an}}}{\lambda^{\mathrm{an}}-1}
$$

\subsubsection{Concentration Estimate}

In the two newly-proposed layouts, it is necessary to have an estimate $\tilde{c}^{\mathrm{mix}}$ of the concentration in the mixer or tank where it is stored. Concentration is calculated by the estimated amount of methanol $\tilde{n}^{\text {mix }}$ and by a measured or estimated solution volume $V^{\text {mix }}$ :

$$
\tilde{c}^{\text {mix }}=\frac{\tilde{n}_{\mathrm{CH}_{3} \mathrm{OH}}^{\operatorname{mix}}}{V^{\text {mix }}}
$$

In turn, the amount of methanol is estimated by integrating the estimated rate of methanol accumulation:

$$
\frac{\mathrm{d} \tilde{n}_{\mathrm{CH}_{3} \mathrm{OH}}^{\operatorname{mix}}}{\mathrm{d} t}=\frac{\rho_{\mathrm{CH}_{3} \mathrm{OH}}}{M_{\mathrm{CH}_{3} \mathrm{OH}}} \dot{V}^{\text {fuel }}-N\left[\frac{I}{6 F}(1-\tilde{b})+\tilde{a} A \tilde{c}_{\mathrm{out}}^{\text {an }}\right]
$$

where the estimated crossover parameters $\tilde{a}$ and $\tilde{b}$ are experimentally determined at $60{ }^{\circ} \mathrm{C}$.

\subsubsection{Two-Mixer System}

This system has one single solution tank where both the degasser effluent and recovered water are mixed. Compared to the reference system's controllers summarized in Table 2, the two-mixer system has a completely different, dynamic controller for concentration and a slightly different implementation for the $\lambda$ control on the anodic side.

Both anodic $\lambda^{\text {an }}$ and inlet concentration are influenced by the fuel pump and the circulation pump in Figure 4, so the controller is chosen to be a $2 \times 2$ MIMO (multi-input, multi-output) feedforward controller.

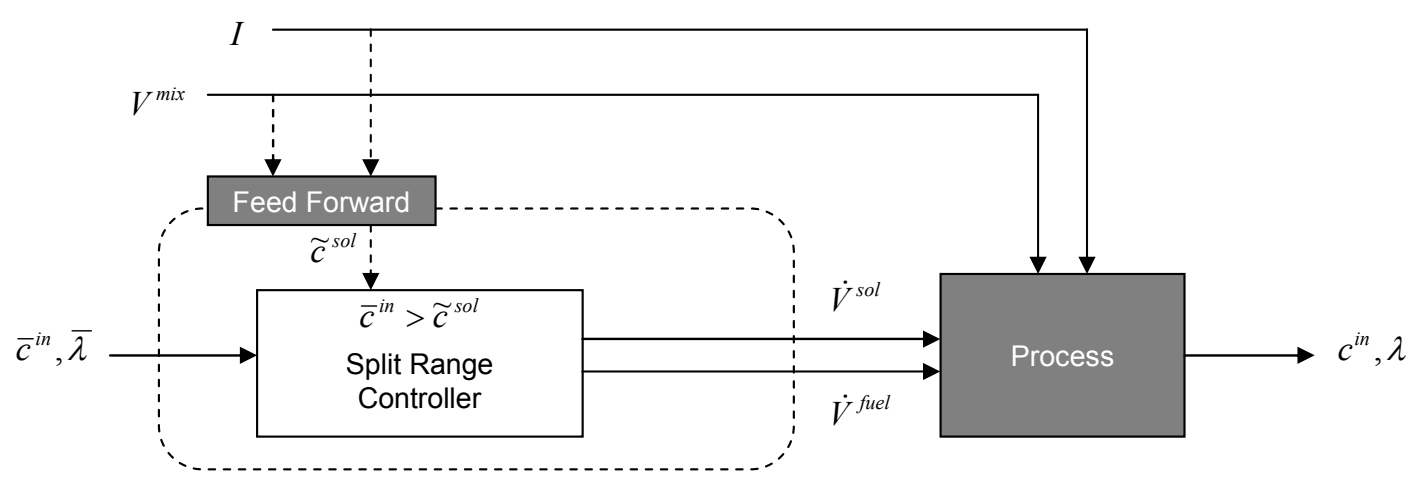

Figure 4. The block diagram of the MIMO feedforward concentration and $\lambda$ controller in the two-mixer system. 
The controller includes an estimator for methanol concentration in the solution tank, implemented as in Equation (15); $\tilde{c}^{\text {mix }}$ is therefore assumed known in the following. It is also assumed that the set-point for inlet concentration $\bar{c}_{\mathrm{in}}^{\text {an }}$ is known from Equation (13).

Two equations must be solved simultaneously to determine $\dot{V}^{\text {fuel }}$ and $\dot{V}^{\text {sol }}$ for $\lambda^{\text {an }}$ and inlet concentration control.

The condition for $\lambda$ control is that the total inflow of methanol into the stack is $\lambda$ times the methanol consumption in the stack due to the anodic reaction and crossover:

$$
\bar{c}_{\text {in }}^{\text {an }}\left(\dot{V}^{\text {fuel }}+\dot{V}^{\text {sol }}\right)=\lambda N\left[\frac{I}{6 F}(1-\tilde{b})+\tilde{a} A \tilde{c}^{\text {mix }}\right]
$$

The condition for concentration control is conditional and depends on whether the estimated concentration in the mixer tank, $\tilde{c}^{\text {mix }}$, is higher or lower than the set-point $\bar{c}_{\text {in }}^{\text {an }}$ : if $\tilde{c}^{\text {mix }}$ is higher, the fuel flow will be set to zero, since negative values are not possible. The condition is expressed as the methanol balance around the inline mixer:

$$
\begin{cases}\bar{c}_{\text {in }}^{\text {an }}\left(\dot{V}^{\text {fuel }}+\dot{V}^{\text {sol }}\right)=\frac{\rho_{\mathrm{CH}_{3} \mathrm{OH}}}{M_{\mathrm{CH}_{3} \mathrm{OH}}} \dot{V}^{\text {fuel }}+\tilde{c}^{\text {mix }} \dot{V}^{\text {sol }} & \text { if } \tilde{c}^{\text {mix }}<\bar{c}_{\text {in }}^{\text {an }} \\ \dot{V}^{\text {fuel }}=0 & \text { otherwise }\end{cases}
$$

The values of $\dot{V}^{\text {fuel }}$ and $\dot{V}^{\text {sol }}$ can be found by solving the linear system of Equations (16) and (17).

\subsubsection{Separate Tank System}

In the separate tank system, the recovered water is gathered in its own tank instead of being mixed with the spent solution from the stack. This allows one to blend the solution from the solution tank with water, in order to produce an anode inlet concentration lower than the one in the solution tank: this can be useful to reduce crossover after a sudden reduction in power output. The separate tank system presents the additional complexity of controlling the liquid level in an additional tank, but the control rules are inspired by the same principles as for the two-mixer system. The previous feedback level controller for the mixer [10] is applied, unchanged, to the water tank; it is therefore the solution tank that will need a new controller.

The three manipulated variables are the flows of neat methanol, solution and water: $\dot{V}^{\text {fuel }}, \dot{V}^{\text {sol }}$ and $\dot{V}^{\text {water }}$. The three control objectives are $\lambda^{\text {an }}$ control, controlling $c_{\text {in }}^{\text {an }}$ and maintaining the level of the solution tank. All three control variables are influenced by all three manipulated inputs, and therefore, a $3 \times 3$ MIMO controller is chosen.

As for the case of the two-mixer system, the controller for the separate tank system includes a concentration estimator (for the solution tank) and assumes that the reference inlet concentration $\bar{c}_{\mathrm{in}}^{\text {an }}$ is given.

The control equations for $\lambda^{\text {an }}$ and concentration control are structurally similar to the case of the two-mixer system. For $\lambda$ control, it is:

$$
\bar{c}_{\text {in }}^{\text {an }}\left(\dot{V}^{\text {fuel }}+\dot{V}^{\text {sol }}+\dot{V}^{\text {water }}\right)=\lambda^{\text {an }} N\left[\frac{I}{6 F}(1-\tilde{b})+\tilde{a} A \tilde{c}^{\text {mix }}\right]
$$


For concentration control, it is:

$$
\bar{c}_{\text {in }}^{\text {an }}\left(\dot{V}_{c}^{\text {fuel }}+\dot{V}^{\text {sol }}+\dot{V}_{c}^{\text {water }}\right)=\frac{\rho_{\mathrm{CH}_{3} \mathrm{OH}}}{M_{\mathrm{CH}_{3} \mathrm{OH}}} \dot{V}_{c}^{\text {fuel }}+\tilde{c}^{\text {mix }} \dot{V}^{\text {sol }}
$$

In an extension of the condition given in Equation (17), either water or fuel flow are stopped depending on the estimated concentration in the solution tank:

$$
\begin{cases}\dot{V}_{c}^{\text {water }}=0 & \text { if } \tilde{c}^{\text {mix }}<\bar{c}_{\text {in }}^{\text {an }} \\ \dot{V}_{c}^{\text {fuel }}=0 & \text { otherwise }\end{cases}
$$

In both Equations (19) and (20), a subscript ${ }_{c}$ has been added to water and fuel flows, to indicate that these are components of the flows that are used to control the concentration. Water and fuel flows are also used to control the solution tank's level, and those components are indicated with the subscript $V$.

The dynamics of the solution volume is an integrator of the volumetric water and fuel flows, which means that it requires feedback to be stabilized; it is assumed that a measurement or estimate $\tilde{V}^{\text {mix }}$ of the solution tank volume is available.

The liquid volume in the solution tank is controlled with a proportional feedback controller ( $\mathrm{P}$ controller), integrated in the $3 \times 3 \mathrm{MIMO}$ controller. The controller attempts to maintain a set-point volume $\bar{V}^{\text {mix }}$ by manipulating water and fuel flows. A simple P controller can be set up as follows [15]:

$$
\dot{V}_{V}^{\text {fuel }}+\dot{V}_{V}^{\text {water }}= \begin{cases}\frac{1}{\tau_{c}}\left(\bar{V}^{\text {mix }}-\tilde{V}^{\text {mix }}\right) & \text { if } \tilde{V}^{\text {mix }}<\bar{V}^{\text {mix }} \\ 0 & \text { otherwise }\end{cases}
$$

Note that, if the actual volume in the solution tank is larger than the set-point, flows are set to zero, since they cannot be negative; over time, the volume of the solution loop will decrease due to electro-osmotic drag in the stack. Constant $\tau_{c}$ is a design parameter corresponding to the desired response time of the controlled process; since the open-loop dynamics of the process is fast, it can be set to a low value, e.g., $60 \mathrm{~s}$.

In addition, the fuel and water flows will need to be dosed, so that the concentration of the resulting solution is $\bar{c}_{\mathrm{in}}^{\text {an }}$, so that the solution volume controller does not interfere with the concentration controller:

$$
\bar{c}_{\mathrm{in}}^{\text {an }}\left(\dot{V}_{V}^{\text {fuel }}+\dot{V}_{V}^{\text {water }}\right)=\frac{\rho_{\mathrm{CH}_{3} \mathrm{OH}}}{M_{\mathrm{CH}_{3} \mathrm{OH}}} \dot{V}_{V}^{\text {fuel }}
$$

The concentration to the anodic inlet can obviously be increased only by the fuel flow rate, while the subscript $_{V}$ indicates the flow rate components for volume control of the solution tank.

The actual fuel and water flows set by the pumps in Figure 5 are the sums of the volume control and concentration control flow components:

$$
\begin{gathered}
\dot{V}^{\text {fuel }}=\dot{V}_{V}^{\text {fuel }}+\dot{V}_{c}^{\text {fuel }} \\
\dot{V}^{\text {water }}=\dot{V}_{V}^{\text {water }}+\dot{V}_{c}^{\text {water }}
\end{gathered}
$$

Virtually splitting the flows into these components is the most straightforward way to enforce the constraint that flows need to be larger than zero across several parts of the MIMO controller. 


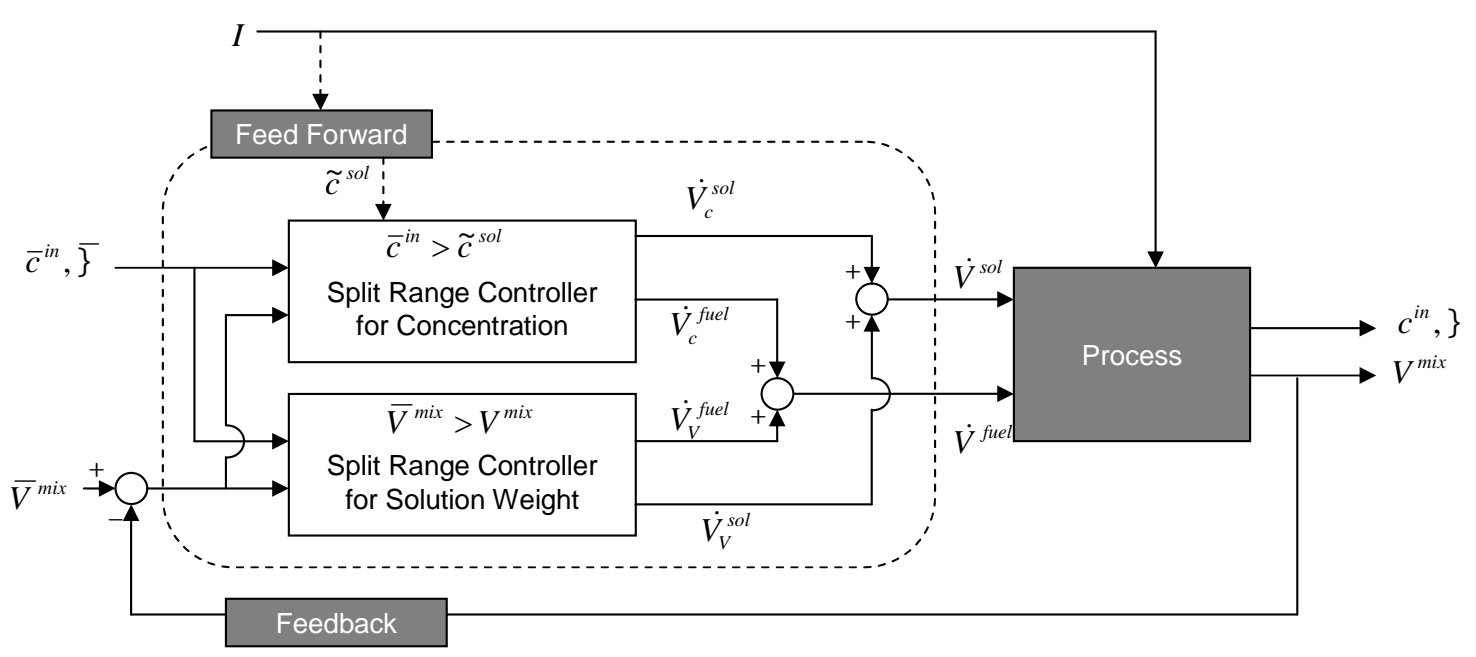

Figure 5. The block diagram of the concentration controller in the separate tank system.

\subsection{Experimental Setup}

\subsubsection{Equipment}

The fuel cell stack (15 W DMFC stack, balticFuelCells, Schwerin, Germany is composed of 9 cells with an active area of $31.5 \mathrm{~cm}^{2}$. Stack temperature is measured with a K-type thermocouple, $50 \mathrm{~mm}$ deep inside of the middle bipolar plate. Insulated, K-type thermocouple probes are used to measure the temperatures of the liquid to prevent corrosion from direct contact with the liquid, while R/S-type thermocouples with the same T-shape casing reported in Zenith and Krewer [11] are employed for the gas phase. Mass flow controllers (SmartTrak C100, Sierra, Monterey, CA, USA) supply air to the cathode and to the anode and cathode coolers. The tubes in contact with liquid phases are Tygon 3350, whereas the others are A-60-G Norprene. The condenser and the loop cooler, tailored for the DMFC systems by IMM, Germany, have a heat-exchanging area of $346 \mathrm{~cm}^{2}$ and $230 \mathrm{~cm}^{2}$, respectively. To minimize heat loss from these two stainless-steel devices, they are insulated with glass fiber and aluminum foil. The solution flow is set by a larger peristaltic pump (MCP Standard, Ismatec, Wertheim, Germany) with an Easy-Load pumping head; the flows from the fuel and water tank are set by smaller peristaltic pumps (Reglo Digital, Ismatec, Wertheim, Germany). The separator and the mixer are designed in-house with strain gauges (FSH01483, Futek, Irvine, CA, USA) to weigh the solution in the mixer, which has an inner volume of $10 \mathrm{~cm}^{3}$ Figure 6).

Methanol concentration is measured on-line by a density meter (MCS, ISSYS, Ypsilanti, MI, USA) to monitor the performance of feedforward controllers. To remove cations from the solution and to prevent particles from damaging the sensitive density meter, an ion exchanger (Amberlyst 15, Merck Chemicals GmbH, Darmstadt, Germany) is employed between glass filters (VitraPOR P16, ROBU, Hattert, Germany). The whole fuel cell system is placed in a climate chamber (PL-3KPH, ESPEC, Osaka, Japan) to control the starting temperature and the ambient temperature. Current is manipulated and voltage is measured by an electric load (ZS512-4SV20NV, Höcherl \& Hackl, Konzell, Germany). All controllers and measurement devices communicate with real-time LabVIEW hardware (cRIO-9072, National Instruments, Austin, TX, USA), programmed in-house. 


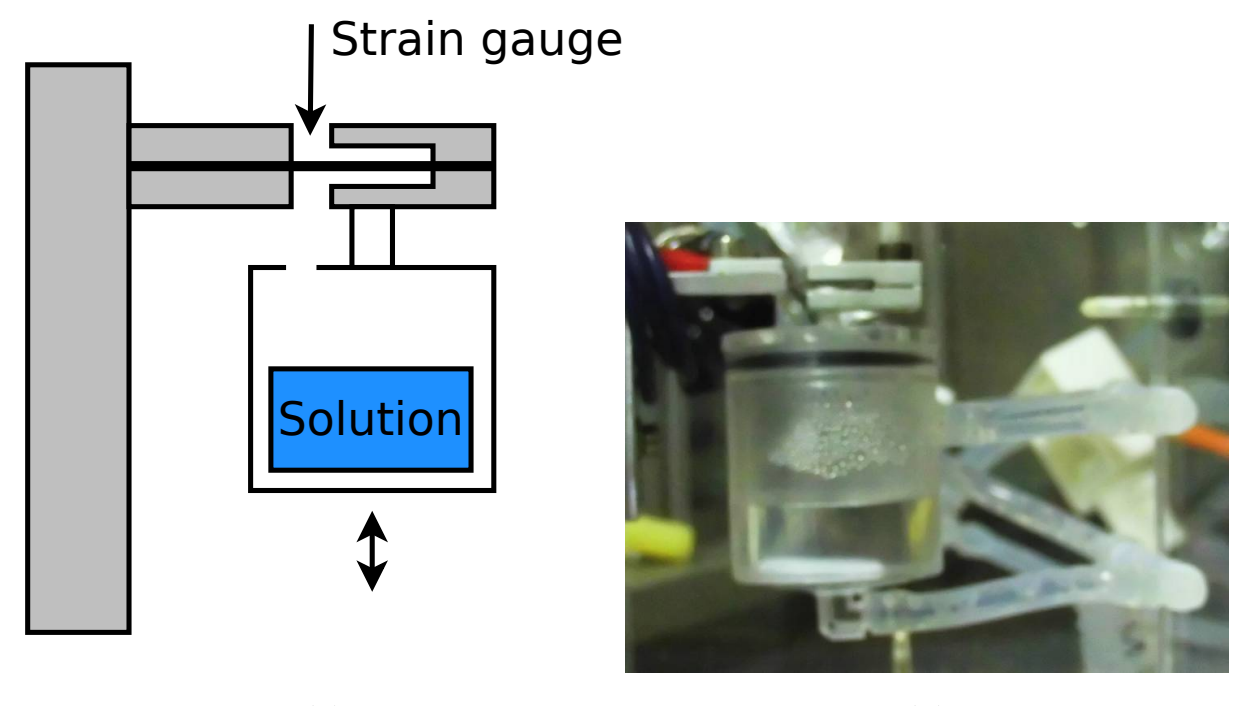

(a)

(b)

Figure 6. (a) The sketch of the weighing mechanism of the tank with the strain gauge; and (b) the picture of the actual mixer attached to the strain gauge.

\subsubsection{Experimental Procedure}

To reduce heat loss from the reactants and products to the massive, metallic loop cooler and the condenser, the starting temperature of the system in the climate chamber is set to the initial temperature $37{ }^{\circ} \mathrm{C}$ of the model simulation. In general, the stack temperature cannot reach the operating temperature $60{ }^{\circ} \mathrm{C}$ due to the heat losses to the environment. While warming up the system, the concentration of the solution is stabilized in the anodic loop for about $1 \mathrm{~h}$. While stabilizing the concentration, the methanol crossover results in heating up the stack around $45^{\circ} \mathrm{C}$. However, before drawing the current from the stack, the climate chamber is shut down to avoid stack cooling by convection. The current profile is composed of stepping down the current to validate the controllers of Sections 3.2.3 and 3.2.4. In this condition, the inlet concentration $\bar{c}_{\text {in }}^{\text {an }}$ is calculated to be smaller than $\tilde{c}^{\text {mix }}$ because the inlet concentration is proportional to the current, per Equation (13). Initially, a current of $3 \mathrm{~A}$ is drawn for $1 \mathrm{~h}$, after which the current is stepped down to $2 \mathrm{~A}$; after maintaining at $2 \mathrm{~A}$ for another hour, a sinusoidal profile is added to the current, with an amplitude of $1 \mathrm{~A}$ and a period of $500 \mathrm{~s}$, to investigate the control performance in presence of variable disturbances. For $3 \mathrm{~h}$, the control schemes presented in the previous sections are operated in the controlling program to validate the simulation, and data are logged via LabVIEW software every second.

\subsubsection{Error Analysis}

The concentration sensor functions by measuring the density of the solution. The producer guarantees an accuracy of $\pm 0.30 \%_{\mathrm{w}}$ in the operating range between $0 \%_{\mathrm{w}}$ and $10 \%_{\mathrm{w}}$, which corresponds to about $0.1 \mathrm{M}$ up to $3 \mathrm{M}$. The operating concentration of this study is between $0.5 \mathrm{M}$ and $2 \mathrm{M}$, well within the validity range. 
The accuracy of the strain gauge is $0.25 \%$ of the rated output at room temperature; if the temperature changes, the error increases with $0.036 \% / \mathrm{K}$. In this study, to reduce the error from temperature variance, the mixer is located in an additional insulated air-filled case.

The electric load has an input error range $0.02 \%$ of real values and a monitoring voltage-offset of $\pm 15 \mathrm{mV}$.

A K-type thermocouple has a theoretical error of $\pm 1.5 \mathrm{~K}$, while an R/S type has $\pm 1.0 \mathrm{~K}$.

\section{Results and Discussion}

To compare the various systems under dynamic operation, the same current profile is applied to all systems (Figure 7a). The simulation results for all three systems are identical, because the voltage is calculated by the Thévenin equivalent circuit and assumed to be independent of temperature and concentration. As such, the results are expected to be derivated from the experiments. At start-up, the experimental voltages of all three systems are lower than in the simulation, as is visible in Figure $7 \mathrm{~b}$. This is attributed to the lower experimental stack temperature. In Table 3, root mean square errors are listed for the relative comparison of the simulation and experimental results.

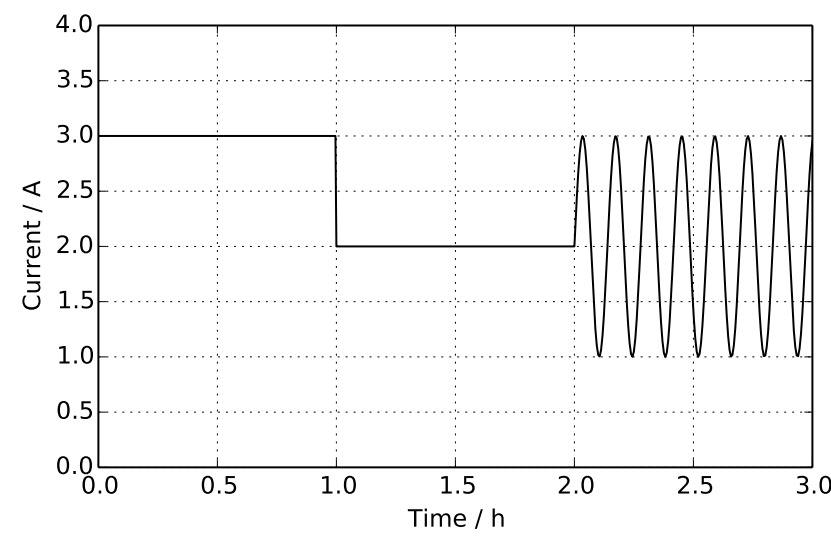

(a)

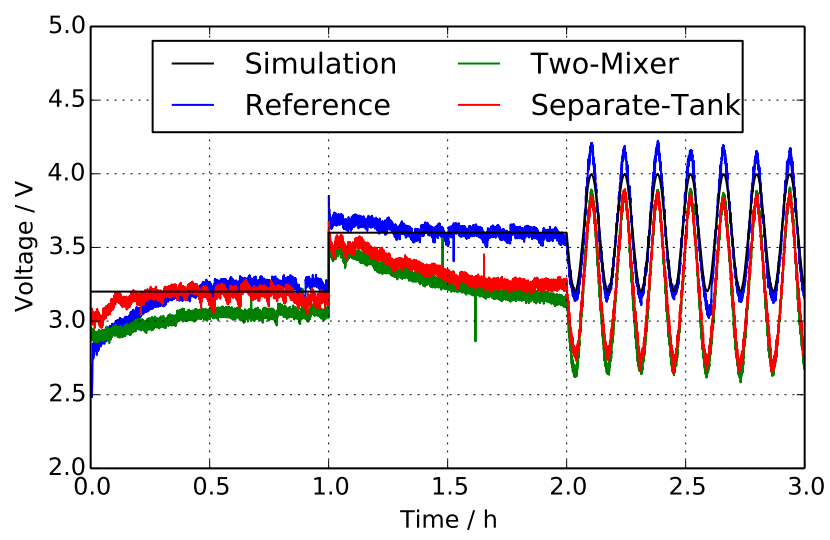

(b)

Figure 7. (a) The input current profile and (b) the resulting output voltage in simulations and experiments for all systems.

Table 3. Root mean squared absolute error between simulations and experiments of each system for stack temperature, inlet and outlet concentration.

\begin{tabular}{cccc}
\hline Parameter & Reference & Two-mixer & Separate tanks \\
\hline Stack temperature $/{ }^{\circ} \mathrm{C}$ & 2.47 (Figure 8a) & 7.85 (Figure 8b) & 5.64 (Figure 8c) \\
Inlet concentration $/ \mathrm{M}$ & 0.151 (Figure 9a) & 0.266 (Figure 9c) & 0.263 (Figure 9e) \\
Outlet concentration $/ \mathrm{M}$ & 0.092 (Figure 9b) & 0.203 (Figure 9d) & 0.175 (Figure 9f) \\
\hline
\end{tabular}




\subsection{Reference System}

There is a certain temperature difference between the experiments and simulations for the reference system, shown in Figure 8a. The difference is caused partly by the non-zero heat capacities of the system elements other than the stack, which result in a slower dynamics, and by heat losses from system elements other than the coolers, which result in a small offset at the steady state.

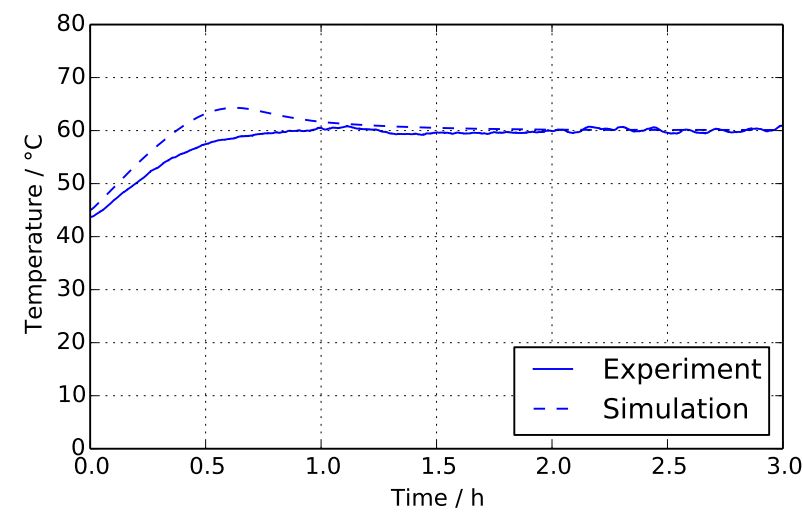

(a)

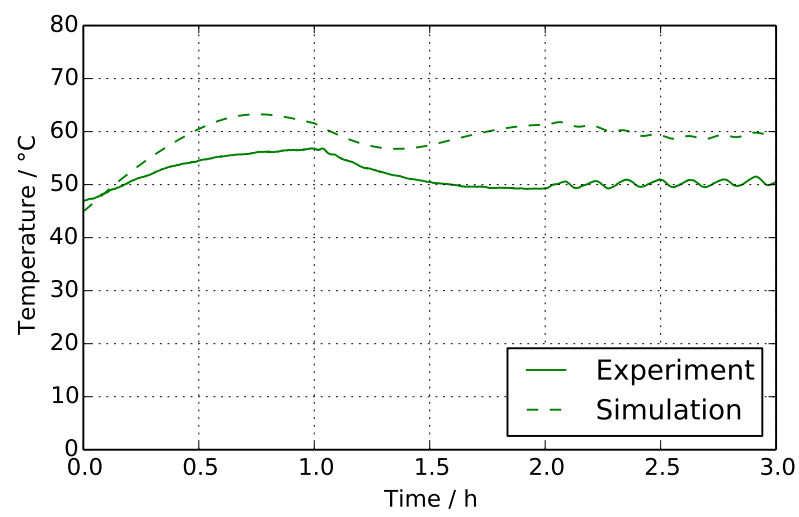

(b)

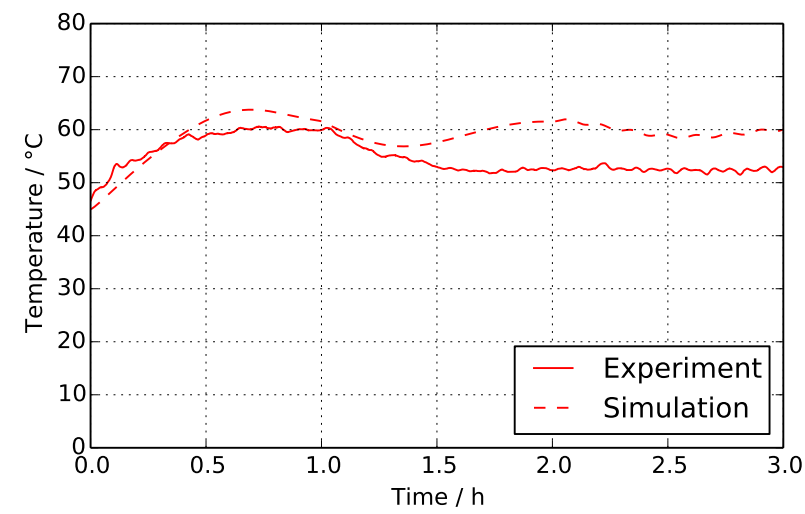

(c)

Figure 8. The temperature profile of the stack in all considered systems: (a) reference system; (b) two-mixer system; (c) separate tanks system.

Application of the feedforward controller to the reference system leads to deviation in the concentration of the simulation and experiments within $\pm 0.1 \mathrm{M}$ from Table 3 at the anodic outlet (Figure 9b). The concentration overshoot at the beginning of the simulation does not appear in the experimental results of Figure 9 because of the presence of liquid in all system elements and the associated transients, which give a slower dynamics than in the simulations. Furthermore, at low temperatures, crossover is overestimated, since the crossover parameters $\tilde{a}$ and $\tilde{b}$ are calibrated at the target stack temperature of $60{ }^{\circ} \mathrm{C}$ : therefore, concentrations are slightly higher for the first hour of simulation. 


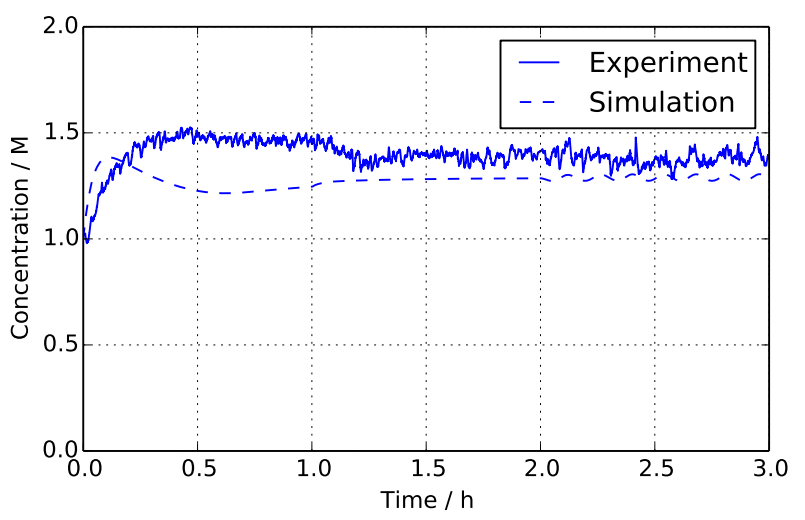

(a)

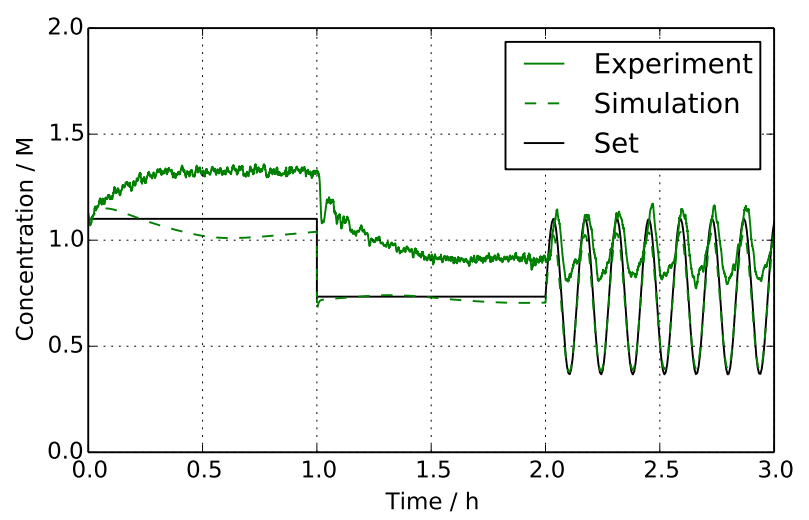

(c)

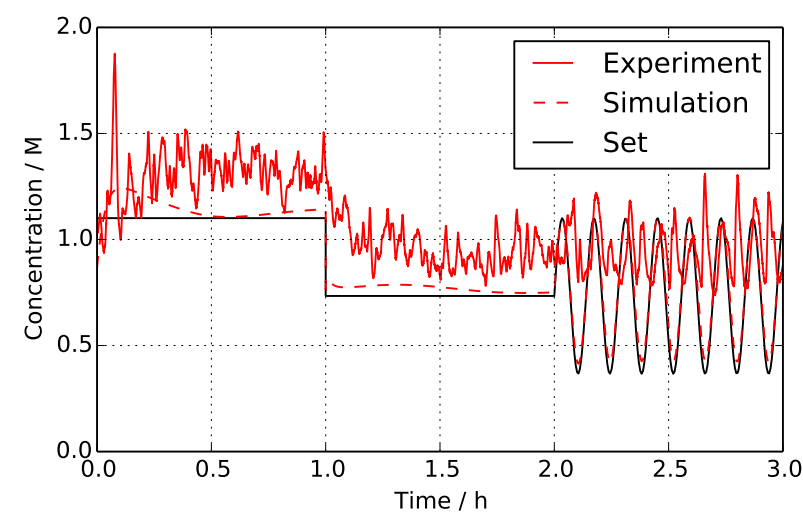

(e)

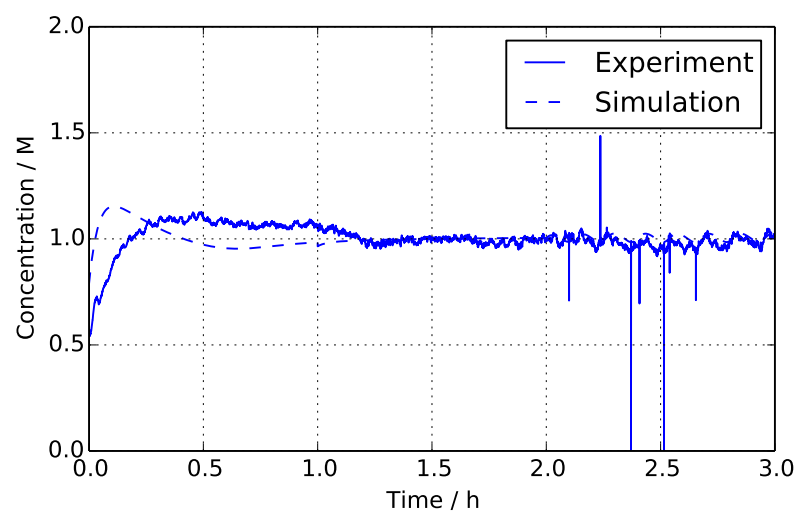

(b)

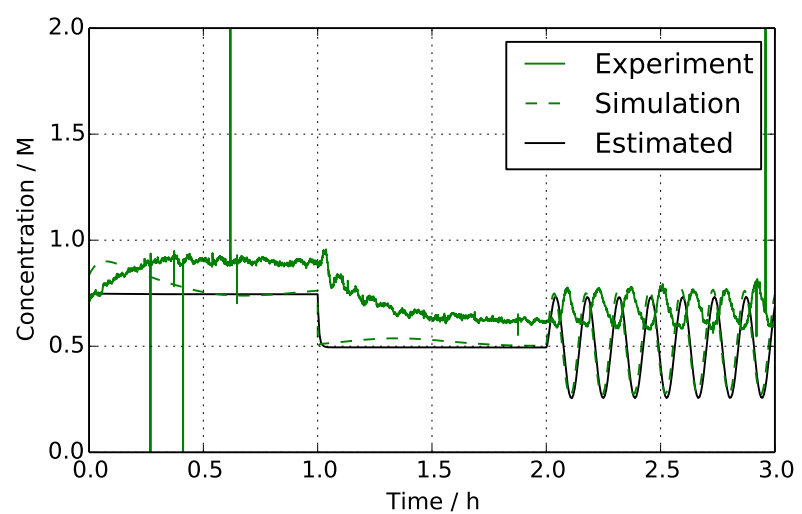

(d)

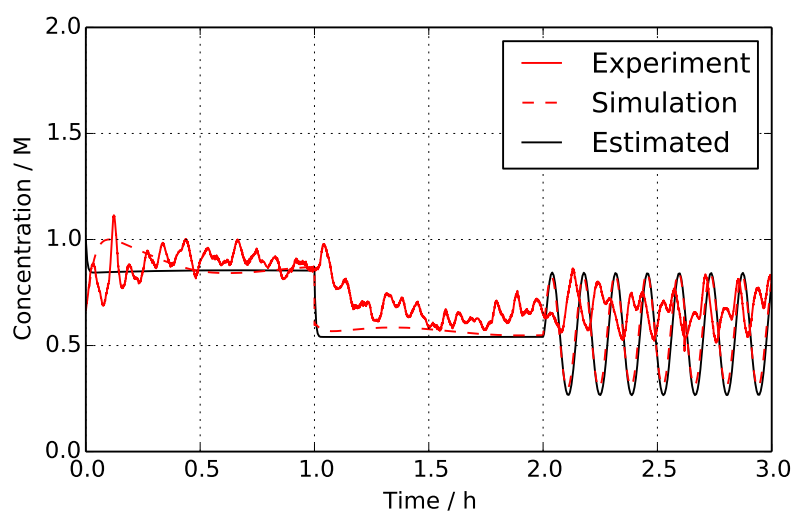

(f)

Figure 9. Stack inlet and outlet concentrations for all systems: (a) reference, inlet; (b) reference, outlet; (c) two-mixer, inlet; (d) two-mixer, outlet; (e) separate tanks, inlet; and (f) separate tanks, outlet. 


\subsection{Two-Mixer System}

In contrast to the reference system, the stack temperature of the two-mixer system cannot reach $60{ }^{\circ} \mathrm{C}$ during the whole period of the experiment, as can be seen in Figure $8 \mathrm{~b}$ and Table 3 . The experimentally-observed low temperature of the stack results from the heat loss from the stack surface, which was not considered in the model. The heat loss is not significant in the reference system, because excessive heat is generated by the large amount of methanol oxidation of the methanol crossover, which is minimized in the two-mixer system to achieve high fuel efficiency. Due to the low stack temperature in the experiment, as shown in Figure 8b, methanol crossover occurs less than in the simulation [13]. However, the fuel flow controller, which is only calibrated at $60{ }^{\circ} \mathrm{C}$ with parameters $a$ and $b$, supplies more methanol to the system than the estimated amount in the simulation. This excessive fuel supply results in a higher concentration in the experiment than that in the simulation, as shown in Figure 9c,d. In real systems, therefore, either $a$ and $b$ need to be given as temperature dependent or the system needs to be better insulated.

\subsection{Separate Tank System}

The solution volume in the solution tank of the separate tank system is lower than the set value owing to the volumetric offset of the P controller (Figure 10c). According to Equation (21), when the solution volume $V^{\text {mix }}$ in the mixer is smaller than the set volume $\bar{V}^{\text {mix }}$, the water flow rate $\dot{V}_{V}^{\text {water }}$ and the fuel flow rate $\dot{V}_{V}^{\text {fuel }}$ are positive. This abundant fuel flow $\dot{V}_{V}^{\text {fuel }}$ for the volume control, besides the fuel flow $\dot{V}_{c}^{\text {fuel }}$ for the concentration control, makes the summated flow rate $\dot{V}^{\text {fuel }}$ larger than that in the two-mixer system. The excessive fuel flow in the separate tank system heated up the stack hotter than that in the two-mixer system, as shown in Figure 8c and Table 3. In the separate tank system, the concentration profiles of the experimental results (Figure 9e,f) are closer to those of the simulation results than those in the two-mixer system in Table 3, because in the separate tank system, the outlet concentration is more precisely estimated using the additional water flow rate $\dot{V}_{V}^{\text {water }}$ than that in the two-mixer system.

The high-frequency noise in the concentration visible in the separate tank system is due to the volume controller for the solution tank: the strain gauge for the solution weight measurement is sensitive to the presence of liquid droplets from the condenser and the degasser, which induce noisy sensor readings and an equally noisy control action. This noise may be easily removed with a low-pass filter in a further refinement of the control system. 


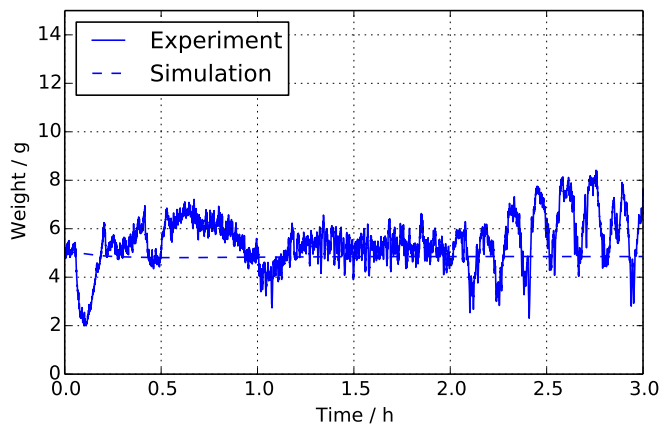

(a)

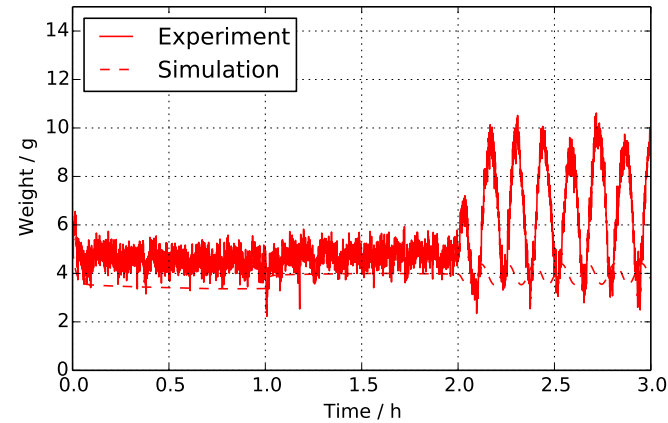

(c)

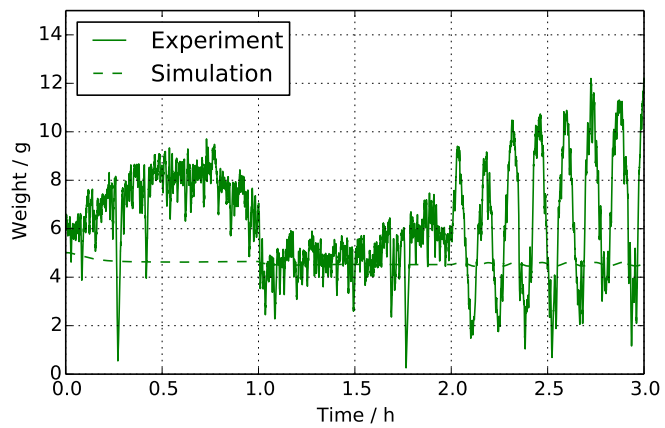

(b)

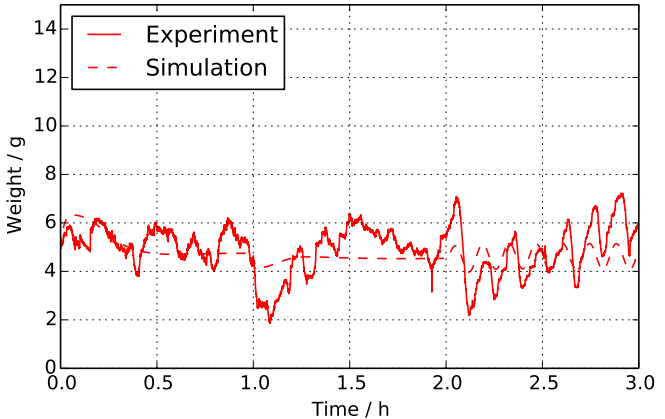

(d)

Figure 10. Solution weight during the operation of the mixer in the various systems and the weight of the water tank in the separate tank system. (a) Reference; (b) two-mixer; (c) separate tanks, solution; (d) separate tanks, water.

\subsection{Faradaic Efficiencies}

As shown in Figure 11a, the efficiency of the two-mixer system is marginally higher than that of the separate tank system, while both are significantly higher than the reference system, especially at low currents.

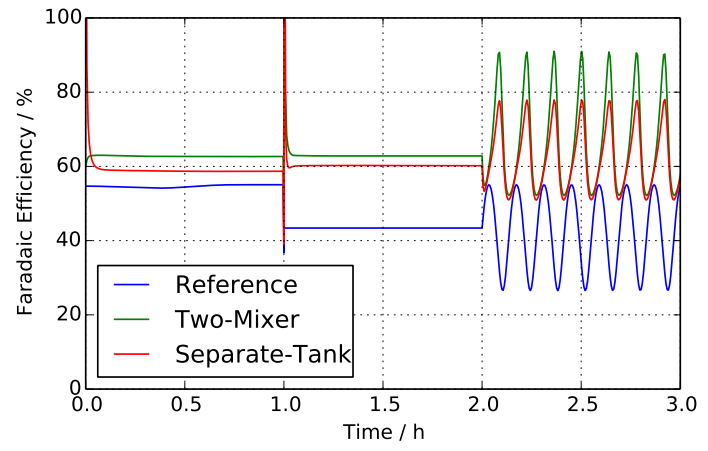

(a)

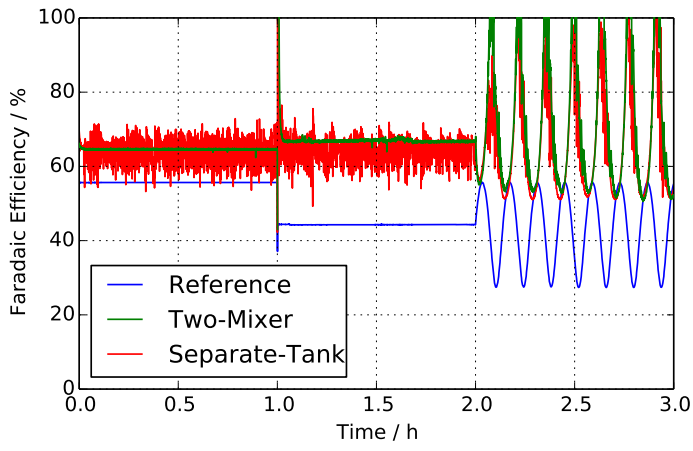

(b)

Figure 11. Faradaic efficiencies of the various systems in simulations and experiments.

(a) Simulations; (b) experiments. 
This is due to the higher concentration maintained by the reference system, which results in higher crossover and reduced efficiency. The simulations are validated by experimental results, as shown in Figure 11b; the noise for the experimental results of the separate tank system is due to the noisy weight measurement, as explained above.

Additionally, supplied fuel flow $\left(\dot{V}_{V}^{\text {fuel }}\right)$ for volume control is consumed and lowers the fuel efficiency below the aforementioned set fuel efficiency $65 \%$ in Section 3.2.1.

\subsection{Liquid Holdup in Solution Tanks}

The solution weight control was able to stabilize the amount of solution and water level (separate tank system only) in all system designs and operating conditions; however, the measured weights fluctuated strongly in experiments.

This is due to the aforementioned sensitivity of the strain gauge to discontinuous two-phase flow: the carbon dioxide produced by the anodic reaction in Equation (1) leaves the degasser discontinuously in Figure 10a-c, while the water tank is independent of the degasser and fluctuates less (Figure 10d).

The rising solution weights at the beginning in Figure 10a,b are attributed to the initially low stack temperature, which allows more water to condense.

In the last hour of the experiments, the weight of the solution tanks oscillates much more than predicted by the simulations; these oscillations are in phase with the current's. This increased amplitude is due to the effect of the varying gas fraction in the stack's anode channels and the tube leading from the anode outlet to the degasser, since $\mathrm{CO}_{2}$ production on the anode is directly proportional to the current, according to Equation (1): as the current increases, more gas is present in the channels, and liquid is displaced to the solution tanks. This effect is not present in simulations, since their model neglects holdup in the stack and tubes.

\section{Conclusions}

Using a dynamically-set inlet concentration in DMFC systems instead of a constant concentration has been demonstrated to significantly improve faradaic efficiency under variable load conditions.

Both of the proposed layouts, two-mixer and separate tank system, have similar time constants for transients in concentration control. The separate tank system is able to track the set concentration with slightly better precision, since part of the anode inlet flow is blended from two reservoirs of known concentration (fuel and water).

The separate tank system has been shown to be subject to oscillations in anode inlet concentration originating from sensor noise propagating through a P controller; a low-pass filter should however be sufficient to ameliorate the issue in a future further development.

All systems, including the original reference system, present significant oscillations in liquid holdup under variable current conditions compared to simulations, due to different rates of $\mathrm{CO}_{2}$ production in the anode and consequent liquid displacement by gas.

In the experiments, the reduced crossover resulted in less heat generation, so that the stack could not reach the set-point temperature of $60{ }^{\circ} \mathrm{C}$ in either of the new proposed systems; as a result, crossover was further reduced by the lower temperature, and the measured concentrations were higher than in 
simulations. This effect is due to the heat losses inherent in a laboratory setup with large exposed areas and should not be an issue in mass-produced, integrated systems.

The two-mixer system is in general preferable, in particular for portable applications, as it comprises fewer components, while featuring essentially the same advantages as the separate tank system.

An avenue for future work is simplifying the two-mixer system with process integration, as was previously done with the reference system [14].

\section{Acknowledgments}

This research was supported by DFG Grant KR3850/1-1 "Analysis and Design of Portable and Autonomous Direct Methanol Fuel Cell Systems".

\section{Author Contributions}

Federico Zenith and Youngseung $\mathrm{Na}$ designed the model and the experiments. Youngseung $\mathrm{Na}$ carried out the experiments. Youngseung $\mathrm{Na}$ and Federico Zenith analyzed and interpreted data. Youngseung Na, Federico Zenith and Ulrike Krewer concluded the scientific findings and prepared the manuscript.

\section{Conflicts of Interest}

The authors declare no conflict of interest.

\section{Latin Symbols}

$\begin{array}{ll}a & \text { Crossover parameter }\left(=1.6748 \times 10^{-6} \mathrm{~m} / \mathrm{s}\right) \\ A & \text { Active area }\left(=0.003 \mathrm{~m}^{2}\right) \\ b & \text { Crossover parameter }(=0.173) \\ c & \text { Concentration }\left(\mathrm{mol} / \mathrm{m}^{3}\right) \\ E & \text { Internal energy }(\mathrm{J}) \\ C_{\mathrm{p}}^{\text {stack }} & \text { Stack heat capacity }(=3000 \mathrm{~J} / \mathrm{K}) \\ i & \text { Current density }\left(\mathrm{A} / \mathrm{cm}^{2}\right) \\ I & \text { Current }(\mathrm{A}) \\ F & \text { Faraday constant }(=96485 \mathrm{C} / \mathrm{mol}) \\ \Delta g_{\mathrm{r}} & \text { Reaction Gibbs free energy }(=-702 \mathrm{~kJ} / \mathrm{mol}) \\ h & \text { Molar enthalpy }(\mathrm{J} / \mathrm{mol}) \\ \Delta h_{\mathrm{r}} & \text { Reaction enthalpy }(=-726 \mathrm{~kJ} / \mathrm{mol}) \\ k_{\mathrm{d}} & \text { Electro-osmotic drag coefficient }(-) \\ M & \text { Molar mass }(\mathrm{kg} / \mathrm{mol}) \\ N & \text { Number of cells }(=9) \\ n & \text { Amount of substance }(\mathrm{mol}) \\ R & \text { Resistance }(=0.4 \Omega) \\ U & \text { Voltage }(\mathrm{V})\end{array}$


$U_{0} \quad$ Open-circuit voltage (V)

$V \quad$ Volume $\left(\mathrm{m}^{3}\right)$

$W \quad$ Weight $(\mathrm{g})$

$y \quad$ Mole fraction (-)

\section{Greek Symbols}

$\beta \quad$ Vapor molar fraction (-)

$\eta \quad$ Overall efficiency (-)

$\varphi \quad$ Faradaic efficiency (-)

$\varepsilon \quad$ Electrochemical efficiency (-)

$\lambda \quad$ Excess ratio (-)

$v \quad$ Current stoichiometric coefficient (-)

$\xi \quad$ Crossover stoichiometric coefficient (-)

$\rho \quad$ Density $\left(\mathrm{kg} / \mathrm{m}^{3}\right)$

$\tau \quad$ Time constant (s)

\section{Superscripts}

$\begin{array}{ll}\text { an } & \text { Anode } \\ \text { cath } & \text { Cathode } \\ \text { cond } & \text { Condenser } \\ \text { deg } & \text { Degasser } \\ \text { fuel } & \text { Fuel } \\ \text { gas } & \text { Gas } \\ \text { water } & \text { Water } \\ \text { liq } & \text { Liquid } \\ \text { mix } & \text { Mixer or solution tank } \\ \text { s } & \text { Side of anode or cathode } \\ \text { sol } & \text { Solution } \\ \text { stack } & \text { Stack }\end{array}$

\section{Subscripts}

flows Flows to the mixer from condenser, degasser or fuel reservoir

in Inlet

j Species

out Outlet

$x \quad$ Crossover

\section{Diacritics}

o estimate

$\overline{0} \quad$ set point

$\dot{0} \quad$ flow $\left(\mathrm{s}^{-1}\right)$ 


\section{References}

1. Carter, D.; Ryan, M.; Wing, J. The Fuel Cell Industry Review 2012; Technical Report for Fuel Cell Today: Hertfordshire, UK, 2012.

2. Sharaf, O.Z.; Orhan, M.F. An overview of fuel cell technology: Fundamentals and applications. Renew. Sustain. Energy Rev. 2014, 32, 810-853.

3. Kamarudin, S.K.; Daud, W.R.W.; Ho, S.L.; Hasran, U.A. Overview on the challenges and developments of micro-direct methanol fuel cells (DMFC). J. Power Sources 2007, 163, 743-754.

4. Kim, J.H.; Yang, M.J.; Park, J.Y. Improvement on performance and efficiency of direct methanol fuel cells using hydrocarbon-based membrane electrode assembly. Appl. Energy 2014, $115,95-102$.

5. Tsai, M.C.; Yeh, T.K.; Chen, C.Y.; Tsai, C.H. A catalytic gas diffusion layer for improving the efficiency of a direct methanol fuel cell. Electrochem. Commun. 2007, 9, 2299-2303.

6. Meyers, J.P.; Bennett, B. Analytical model to relate DMFC material properties to optimum fuel efficiency and system size. J. Power Sources 2011, 196, 9473-9480.

7. Park, J.Y.; Seo, Y.; Kang, S.; You, D.; Cho, H.; Na, Y. Operational characteristics of the direct methanol fuel cell stack on fuel and energy efficiency with performance and stability. Int. J. Hydrog. Energy 2012, 37, 5946-5957.

8. Wu, W.; Lin, Y. Fuzzy-based multi-objective optimization of DMFC system efficiencies. Int. J. Hydrog. Energy 2010, 35, 9701-9708.

9. Arisetty, S.; Jacob, C.A.; Prasad, A.K.; Advani, S.G. Regulating methanol feed concentration in direct methanol fuel cells using feedback from voltage measurements. J. Power Sources 2009, 187, 415-421.

10. Zenith, F.; Krewer, U. Modeling, dynamics and control of a portable DMFC system. J. Process Control 2010, 20, 630-642.

11. Zenith, F.; Krewer, U. Simple and reliable model for estimation of methanol cross-over in direct methanol fuel cells and its application on methanol-concentration control. Energy Environ. Sci. 2011, 4, 519-527.

12. Zhao, T.; Xu, C.; Chen, R.; Yang, W. Mass transport phenomena in direct methanol fuel cells. Progress Energy Combust. Sci. 2009, 35, 275-292.

13. Scott, K.; Taama, W.; Kramer, S.; Argyropoulos, P.; Sundmacher, K. Limiting current behaviour of the direct methanol fuel cell. Electrochim. Acta 1999, 45, 945-957.

14. Zenith, F.; Na, Y.; Krewer, U. Effects of process integration in an active direct methanol fuel-cell system. Chem. Eng. Process. Process Intensif. 2012, 59, 43-51.

15. Skogestad, S. Simple analytic rules for model reduction and PID controller tuning. J. Process Control 2003, 13, 291-309.

(c) 2015 by the authors; licensee MDPI, Basel, Switzerland. This article is an open access article distributed under the terms and conditions of the Creative Commons Attribution license (http://creativecommons.org/licenses/by/4.0/). 